\title{
De repente Índia...
}

De repente,

tudo parece incomum... Incoerente em cada gesto, indigesto a cada mordida.

De repente, acostumamo-nos com a comida, ardida demais...

Depois disso, nos vêm as respostas, mesmo sem sabermos a questão!

Fato é que o não simplesmente não existe, que o sim é mais ou menos, num sorriso meio triste, e talvez seja eu o diferente! De repente... 06/02/2009 João F. A. Cunha*

* Mestrando FFLCH / DLCV/USP- Projeto: "Uma Leitura Crítica de Jacó e Dulce cenas da vida indiana, à luz do realismo de Eça de Queirós" (FAPESP) - Contato: joaofacunha@usp.br 
Este texto surgiu inicialmente com o intuito de apontar algumas transformações em minha pesquisa de mestrado, após viajar para Goa, em fevereiro deste ano. A princípio, ele parecia informal demais, com trechos narrativos, e provavelmente não funcionaria muito bem como relatório de bolsista. Contudo, ao tomar conhecimento do Diário Acadêmico, percebi que bastavam alguns retoques para chegar ao formato apropriado. Falar pela primeira vez sobre minhas experiências na Índia, com absoluta frieza acadêmica seria algo muito complicado. Sendo assim, procurarei narrar um pouco do que vi, sem perder de vista a proposta desta revista.

$\mathrm{Na}$ área de Estudos Comparados de Literaturas de Língua Portuguesa, frequentemente nos deparamos com as dificuldades de estudarmos autores e obras que ocupam uma condição marginal. As literaturas africanas superam mais e mais, a cada ano, essas dificuldades, seja pela crítica que vem sendo desenvolvida, seja pelos próprios autores, que vêm ganhando maior notoriedade $\mathrm{e}$ reconhecimento em todo o mundo de língua portuguesa. Mirando-se nesse exemplo, pesquiso a literatura goesa, imaginando um dia minimizar sua marginalidade. É claro que, no caso específico de Goa, esperar o reconhecimento por obras inéditas, como vem acontecendo em Angola e Moçambique, no período pós-independência, é quase impossivel, pois ao contrário dos países mencionados, Goa, seguindo a determinação da União Indiana, adotou desde 1961 o inglês e o hindi como linguas nacionais e posteriormente o concanim como lingua oficial do estado. Desse modo, não demorará muito para que os goeses que escrevem em lingua portuguesa estejam praticamente "extintos".

Por outro lado, o interesse pelo estudo crítico de uma literatura capaz de combinar uma série de elementos distintos, como é o caso da literatura produzida em Goa, parece crescer. Na maior parte das vezes sobra curiosidade, mas falta material para desenvolver uma grande pesquisa, e este foi, sem dúvida, o motivo dessa viagem para a Índia durante meu mestrado. Não por acaso, tive como companheiro de viagem meu orientador, o Prof. Dr. Hélder Garmes, que desenvolve há 
mais de dez anos sua pesquisa na área, e que também viveu sua primeira experiência em solo indiano.

Quando cheguei em Mumbai, o prof. Hélder já estava instalado há cerca de quinze dias, o que ajudou a amenizar o impacto da minha chegada. Nossa dificuldade de compreensão de aspectos organizacionais, éticos, culinários, higiênicos e outros tantos ligados à cultura do povo indiano, foi tão grande que não vejo possibilidade de explicá-los fidedignamente. Reproduzo aqui a primeira lição marcante na minha chegada:

- João, aqui em Mumbai tudo é complicado.

Entendi o porquê, quando perdemos o avião para Goa por culpa dos taxistas. Entre o aeroporto internacional e o doméstico tivemos três motoristas diferentes. Um manobrou o carro, outro nos levou até a metade do caminho e o terceiro nos deixou no destino, cinco minutos após o voo partir. Todos queriam gorjeta!

Pegamos outro avião e finalmente pude pisar em Goa. Coqueiros e coqueiros e coqueiros, placas e nomes em português, entre saris, ultrapassagens na contramão, muitas buzinas, autoriquixás (os famosos triciclos) e logo senti como era estar em solo goês. A quantidade de igrejas, capelas e símbolos cristãos chamam a atenção, tanto quanto os monumentos e as construções hindus.

Meu objetivo particular era reunir material para uma melhor leitura do romance Jacó e Dulce - cenas da vida indiana, obra central no meu mestrado. Nosso objetivo conjunto, mapear o maior número possivel de referências à literatura de língua portuguesa na Índia, copiar e comprar o quanto pudéssemos de material bibliográfico e, naturalmente, tentar compreender melhor algumas peculiaridades daquela cultura. Concentramos nossas atividades em duas bibliotecas: a Biblioteca Central de Panaji (antiga Panjim ou Nova Goa) e o Xavier Centre of Historical Research, uma vez que o Arquivo de Goa, o mais antigo arquivo europeu no Oriente, tinha material que no momento não nos interessava diretamente, relativo à documentação histórica dos séculos XVI ao XVIII. Dentre as muitas obras consultadas e 
digitalizadas, ganham destaque na minha pesquisa as edições em português do romance que estudo, incluindo sua primeira publicação em folhetim (1895-1896), no periódico semanal O Ultramar, além de sua versão em inglês. A mesma verificação de edições variadas pôde ser feita com o romance Os Brâmanes de Francisco Luís Gomes, que inaugurou o gênero, em lingua portuguesa, na Índia. Por outro lado tivemos contato pela primeira vez com obras como: Os Maharatas - paisagens indianas (1894), Quadros Históricos de Goa (1864-1865), Fastos da Minha Terra (1890) Glossário Luso-Asiático (1988) e Bodki (c.1925).

Além de obras ficcionais, etnográficas e historiográficas, pudemos conhecer textos recentes de crítica literária, em grande parte ligados a professores da Universidade de Goa, como a análise das representações da mulher na literatura goesa, feita pela profa. Fátima Gracias em The many faces of Sundoren - women in Goa (2007), ou Episódio Oriental: Readings in Indo-Portuguese Literature (2007), uma coletânea de ensaios, publicada pela Fundação Oriente, como, por exemplo, The Konkani Flavour in Goa's Spoken Portuguese, as witness in GIP's Jacob e Dulce, de Olivinho Gomes, e Índia Mitica em Português - Adeodato Barreto e o Eterno Retorno do pesquisador brasileiro Everton Machado (da Universidade de Paris IV).

Também é relevante a pesquisa feita por Rochel Pinto, sobre a relação entre imprensa e politica em Goa, destacando algumas das principais manifestações literárias indo-portuguesas, publicada pela Oxford University Press com o título Between Empires - prints and politics in Goa (2007).

Esses poucos exemplos procuram dar um panorama das leituras a que tivemos acesso. No entanto, nossa vivência no ambiente representado nos textos literários, no espaço físico dos personagens de Jacob e Dulce, nas salas das casas goesas foram ainda mais importantes. Fomos recebidos carinhosamente pelas mais diversas pessoas (padres, professores, comerciantes etc.), com as quais realizamos entrevistas curtas, mas profundamente esclarecedoras, sobre aspectos socioculturais de Goa. Elaboramos um questionário, 
com perguntas bem genéricas, que permitisse que os entrevistados falassem de coisas que nos interessavam - como a relação entre cristianismo e castas sociais, o ritual dos casamentos, a mistura entre cultura indiana e portuguesa -, mas também lhes dava margem para falarem daquilo que achassem mais relevante para nossa compreensão daquele universo. Ainda não conseguimos organizar esse material, mas sua importância é inegável, não apenas para minha pesquisa, como para todos que procuram uma leitura mais plural do universo por onde nossa lingua circula.

Durante nossa estadia, ainda participamos de uma reunião, mediada pela professora Ernestine Carreira (Université de Provence, França), com diversos estudiosos, interessados em preservar a cultura de língua portuguesa em Goa. O centro do debate foram os acervos privados das grandes famílias goesas, assim como a necessidade de se trabalhar para a preservação de uma série de documentos e livros, que por má conservação, podem se perder em pouco tempo. Uma realidade com a qual me deparei na pesquisa dos periódicos, quando constatei que muito do que Gip - como era conhecido o autor que eu estudo publicou em jornais está irrecuperavelmente consumido pelos anos. O estabelecimento desse interesse comum é, sem dúvida, um ponto de partida para que se desenvolva o debate crítico, sobre literatura e cultura goesas em âmbito internacional, envolvendo a Universidade de São Paulo, a Université de Provence, a Universidade de Goa e a Universidade Nova de Lisboa, todos ali representados.

Diante disso, apesar de poder dizer que meu projeto avançou mais em um mês do que nos últimos quatro anos, tenho consciência de que, para quem não acompanha diretamente minha pesquisa, tal evolução é quase imperceptivel, tendo em vista as poucas referências dadas. Portanto, encerro este texto buscando exemplificar esse impacto, comentando as primeiras linhas de Jacó e Dulce - cenas da vida indiana. 
Ele chamava-se, curta e plebeamente, Jacó Jacó Avelino Dantas.

Natural da cidade de Breda, gãocar da respectiva comunidade agrícola de sangue real, ia em 25 anos, quando ocorreram os fatos que vou relatar.

Sem dúvida, a sua família era nobre e principal, e fruía a glória platônica e sem proveito digno de menção, de pertencer ao primeiro vangôr. (COSTA, F. J., Jacob e Dulce - scenas da vida indiana. Tipografia Sadananda: Pangim, 1974. (p. 01)

Ao apresentar Jacó aos seus leitores, o autor destaca características de extrema importância na cultura indiana, como, por exemplo, a origem de sua família. Concomitantemente à sua descrição, toda a linhagem do protagonista, até os primórdios de Goa, é rapidamente mencionada. Porém, para percebermos isto é necessário entender principalmente duas palavras: gãocar e vangôr.

Gão significa aldeia, uma das primeiras divisões a ser feita em território goês. Gãocares eram os representantes da associação agrícola da aldeia, e vangôr era todo aquele que descendesse dos fundadores da aldeia, tendo por isso direito a votos no conselho, além de uma parte significativa dos lucros gerados com a venda coletiva dos cocos. Confesso que sequer sabia da existência de terras de uso coletivo em comunidades indianas, bem como, não imaginava a que ponto chega a valorização da origem de uma família para eles. Diante disso percebi que, compreender parcialmente estes pontos, impossibilitou meu entendimento anterior das ironias no comportamento da família de Jacó, durante o acerto de seu casamento com Dulce, comprometendo assim a leitura do romance. 


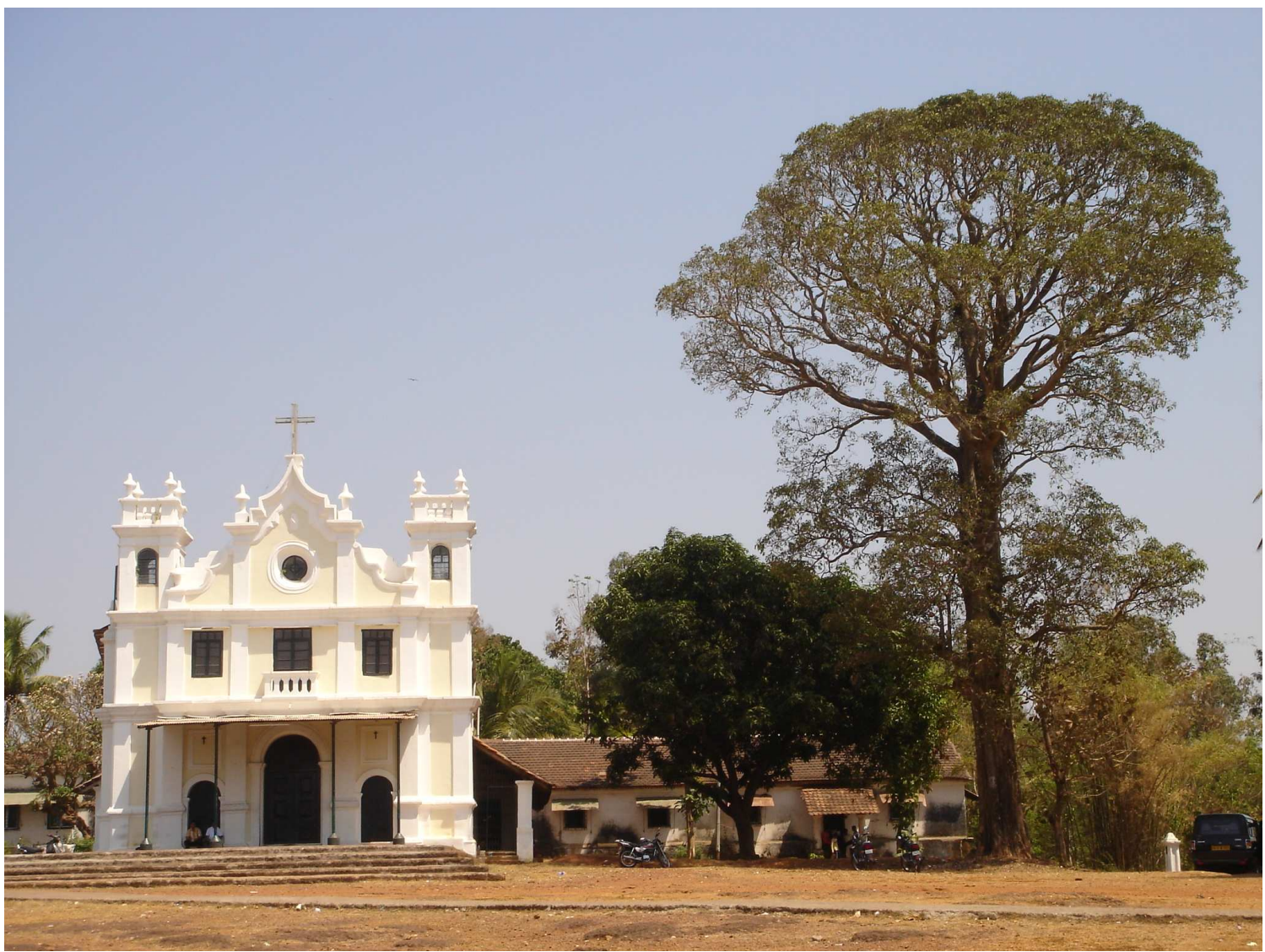

Capela de Nossa Senhora da Piedade do Monte - em Margão. (Apesar de Jacó e Dulce ser ambientado em uma cidade fictícia chamada Breda, a referência à capela no monte, feita pelo narrador, é um dos principais indícios de que Breda representava o bairro da Borda em Margão)

Há muito trabalho a ser feito, se desejarmos verdadeiramente diminuir a distância entre a bibliografia em língua portuguesa existente em Goa (um patrimônio que talvez não tenha possibilidade de se ampliar, mas certamente não poderá ser perdido) e as literaturas de lingua portuguesa na África, no Brasil e em Portugal. Mas nessa viagem pude entender melhor a seriedade de se pesquisar autores e obras que parecem insignificantes aos olhos comuns, pude ver a dedicação de um grande pesquisador em busca de material para mais uma etapa acadêmica, e pude sofrer com a pimenta e a água indianas. Só indo lá para entender... 


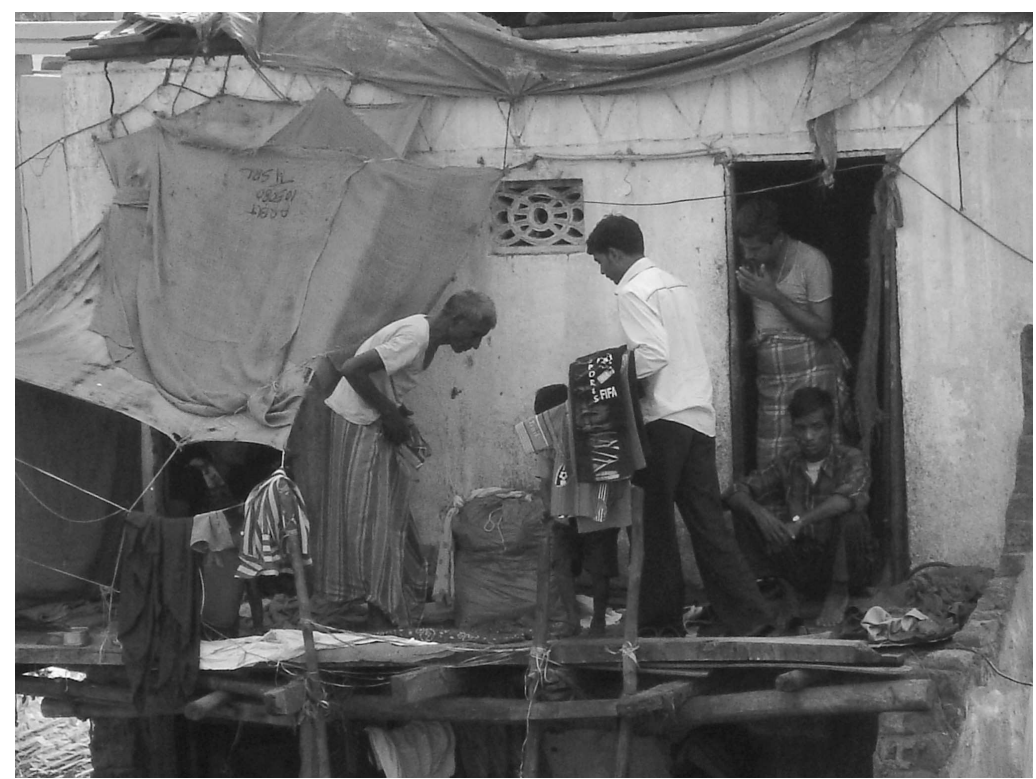

Favela em Mumbai, às margens da ferrovia que corta a Índia de Norte a Sul

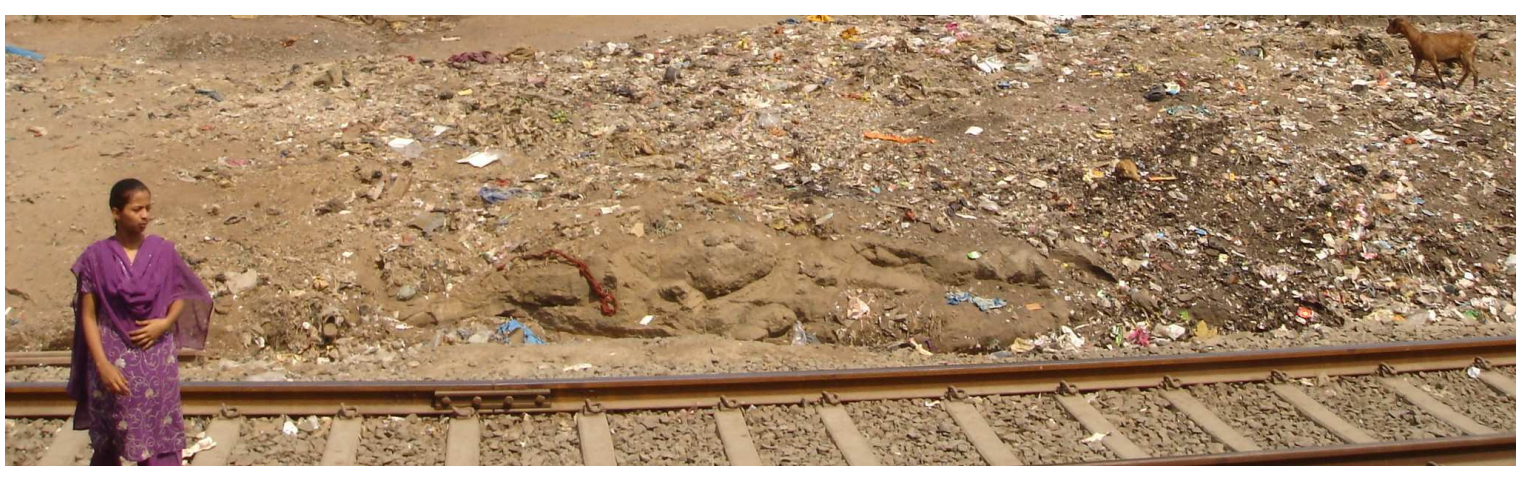

Indiana vestindo sari, cruzando a ferrovia, nas proximidades de Agra

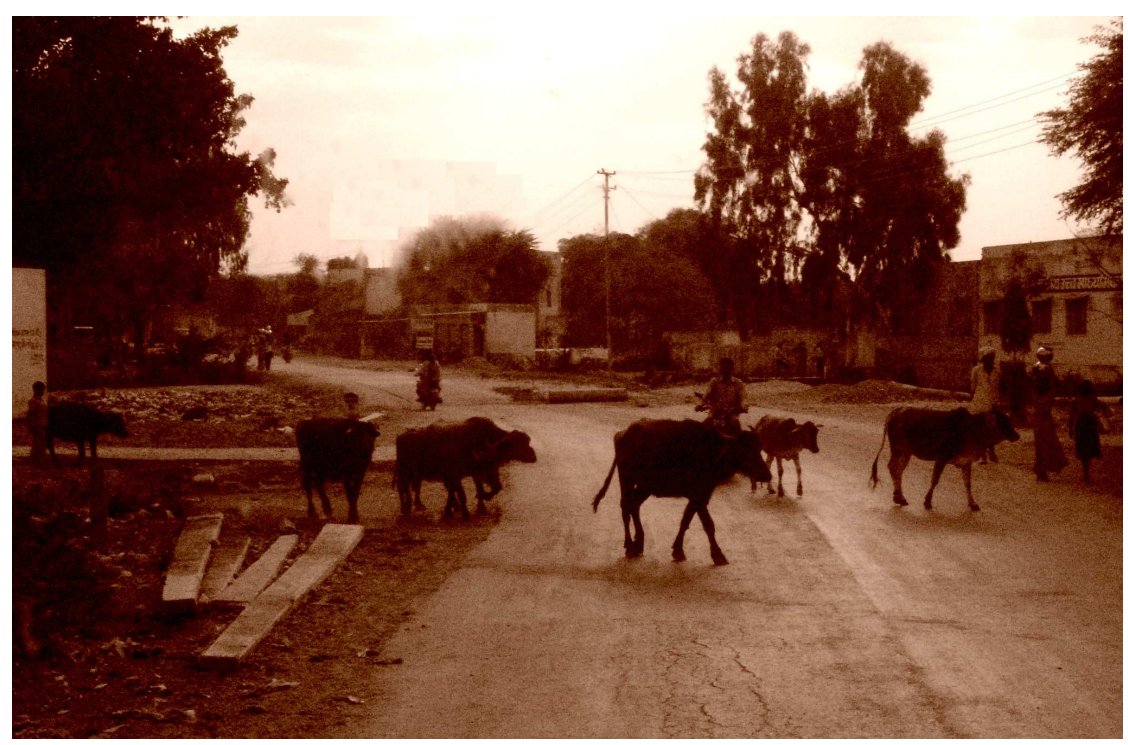

Búfalos cruzando a rodovia entre Jaipur e Udaipur, no Rajastão 


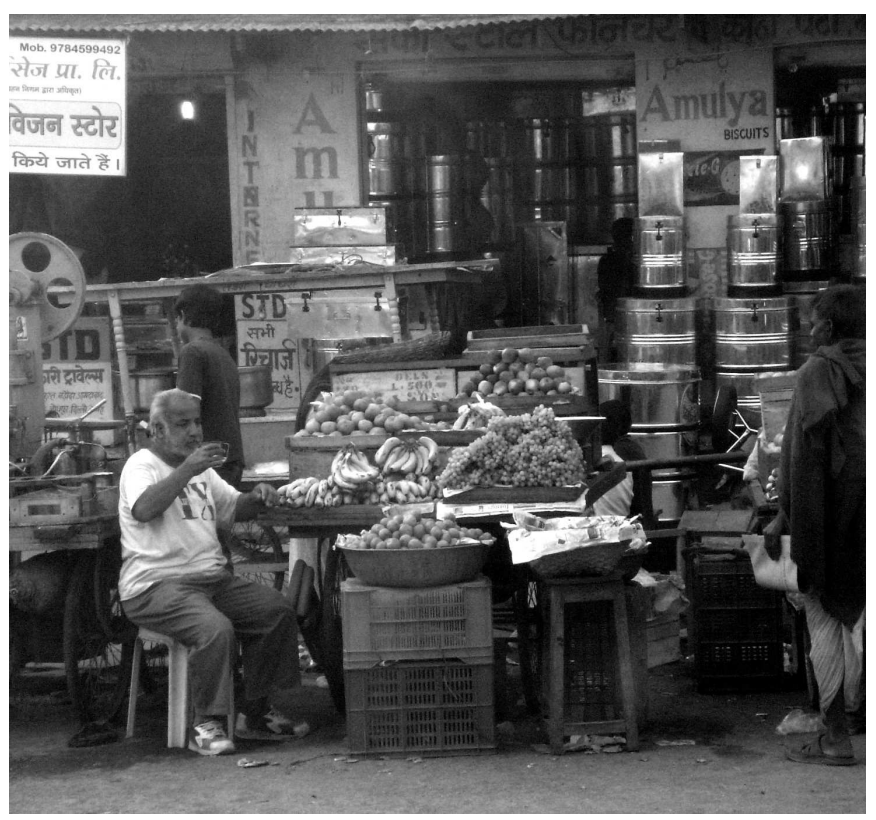

Vendedor de frutas, em uma parada de ônibus, em uma vila de nome impronunciável do Rajastão

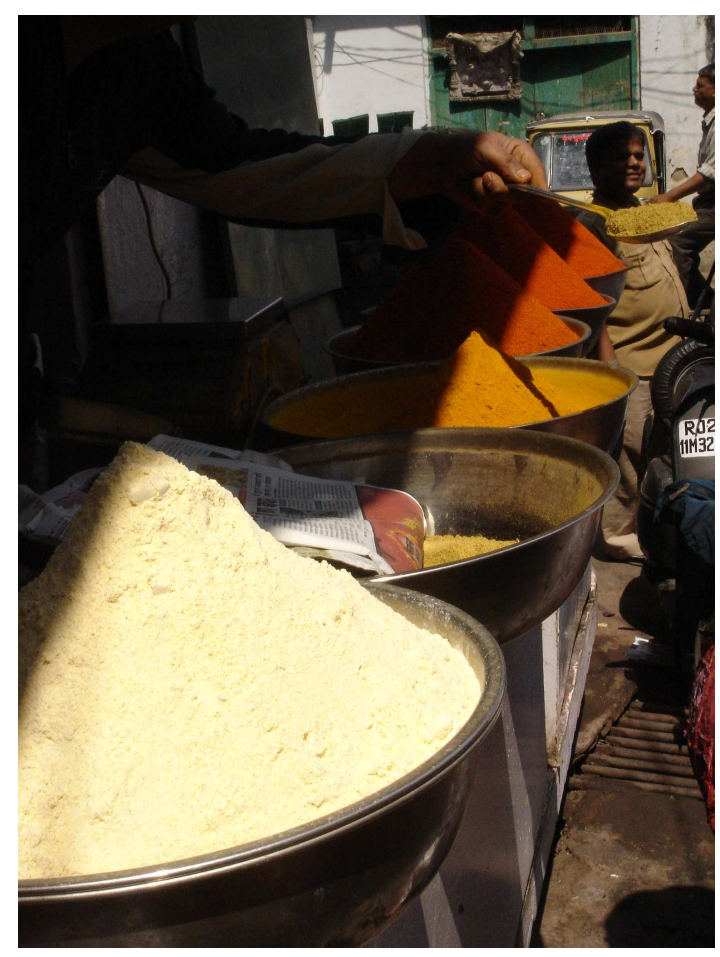

Venda de especiarias, no mercado popular em Udaipur, no Rajastão (pimenta branca; masala; curry; páprica; e outras combinações de temperos) 